degree of vitality, and to retard the increase of the classes possessing the lower degrees of vitality. It is, however, within the power of man greatly to aid the operations of nature, by offering additional rewards to the higher degrees of labour, and affording additional facilities for the increase of that part of the population which is now ascertained to possess the highest degree of vitality.

October, 1854 .

\section{OBSERVATIONS ON CHOLERA.}

By ROBERT MOLLOY, M.D.

AN attentive perusal of the many valuable papers on cholera which have appeared in THE LANCET, has forced me to conclude that we, as a professional body, have departed somewhat from the track of legitimate inquiry. In our anxiety to obtain a cure or antidote for this formidable disease, we have overlooked the Baconian rule of progression from the "better to the less known," and have forgotten that the surest way to secure available information is to study the antecedents and accompaniments of this, as well as of every other epidemic. The late outbreak afforded me an opportunity of making a few observations upon some of the phenomena which precede and attend upon cholera; and as no reference that $I$ am aware of has been made to them by previous writers, I hasten to lay them before yon as briefly as I may.

Olsertation 1.-During the prevalence of the cholera no one was absolutely uell. All I came in contact with, with scarcely an exception, were suffering from furred tongue, mal-aise, languor, depression of spirits, pains in the back and limbs, with other symptoms of low fever; indicating the existence of "something" of general influence (predisposing).

Observation 2.-Universality of diarrhoea, even in persons usually least disposed to such attacks. When diarrhoa was not alssolntely present, there were fugitive pains in the bowels, flatulent rumbling and roaring of intestines, to such an extent that it might be heard frequently several yards off; and the evacuations from the bowels, when examined, were lumpy, containing little or no bile. This condition almost invariably terminated in diarrhoa, and has been well described by "M.D." in THe LaNCET of Nov. 4th.

Observation 3. - Tendency of diarrhcea when it first appeared, about the end of July and commencement of August, to pass into dysentery, with bloody motions, intense and distressing tenesmus, occasionally going on to prolapse of anus, both of which would persist for days after the intestinal secretions had been rendered healthy.

Observation 4.-The peculiar mode in which diarrhoa commonly made its appearance; the instantaneous nature of the attack, with the impossibility of resisting or even controlling it by any exertion of will; and the great force with which the secretions were ejected from the bowels.

Observation 5. - Singular manifestation of the cholera poison, wholly different from what we have seen before, (at least, I have never seen it.) Many patients in a state of collapse would seem to improve: vomiting, purging, cramps, would all leave, warmth and pulse return, reaction be established, and at the time when a favourable prognosis might fairly be given, and hope at the highest, they would quietly pass away in a painless sleep. Is this due to a compound poison-a narcoticoirritant? Like arsenic, giving rise to extreme irritation of the digestive mucous membrane primarily, and at length causing death by its narcotic action on the nervous centres?

Observation 6.- On the subsidence of cholera, typhus and other fevers of a low type resumed their influence; bnt it has been especially followed by an epidemic affection of the glands of the throat and mouth, external as well as internal, which become suddenly enlarged, and acutely painful, without any disposition to pass into suppuration or ulceration.

As the few remarks which succeed are intended to be speculative and suggestive rather than explanatory, I would venture to draw some deductions from the pre-announced observations, which I shall put interrogatively, in order the better to fix the attention and elicit the opinions of those of your correspondents who have had the greatest experience in the treatment of this virulent disease.

Conclusion I.-That a stage preceding diarrhoea must be admitted? This may be caused by starvation, excess in drink, exhaustion, illness, mental anxiety, anything in short which reduces the constitutional powers below par.

The sequence may be thus stated:-Low fever, or other systemic derangement-diarrhoa-collapse.

Conclusion 2. - That the presumable seat of disease is the gastro-intestinal mucous membrane?
Conclusion 3. - That cholera is contagious? Using the term as synonymous with infectious. A peculiar poison in cholera is now very generally admitted, and if the preceding observations be correct, causation by predisposition is complete-a poison and a fit recipient.

Conclusion 4. - That the purgative or "eliminatire" treatment is not the rational treatment may be clearly demonstrated by the following reasons:-That cholera has not unfrequently been caused by the use of aperients - that the excessive discharge does not cure itself-that it is inadmissible, and would be highly injurious in diarrhcea following fevers, the diarrhcea of phthisis, of exhaustion, or of dysentery-and by the nearly unanimous experience of the contrary practice adopted in the diarrhcea which almost invariably precedes cholera. Besides, if the truth of the fifth observation be conceded, it would tend to show that death does not necessarily result from the presumed drain of the serum of the blood, and its consequent thickness, but from the narcotic influence of the cholera poison upon the nervous centres.

November, 1854.

\section{EARLY OPERATION FOR HARE-LIP.}

\section{By ALEXANDER DOUGLAS, Esq., M.R.C.S., Stratford.}

THE earliest operation on record for this malformation, I believe, was performed by me on a child now ten weeks old. I attended the mother in her labour, which was a natural but rather protracted one, it being her first. There was no tumefaction of the child's scalp or features, which were strong and healthy. Two hours after birth, finding the child tranquil, I operated in the usual manner, it being a case of single hare-lip, without fissure of the palate; instead of pins I used fine sewing needles, cutting off the points with pliers. There was but trifling hæmorrhage. The third day the child drew the breasts, and on the fourth I removed the needles. The case was very successful, having healed by the first intention.

My reasons for operating thus early were-Nature's Iaw, that infants bear much injury during birth without fatal results, and their capability of fasting for the first three days after birth, milk being seldom secreted until then.

November, 1854.

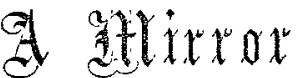

OF THE PRACTICE OF

\section{MEDICINE AND SURGERY IN THE}

\section{HOSPITALS OF LONDON.}

Nulla est alia pro eerto noseendi via, nisi quam plurimas et morborum et dissectionum historias, tam aliorum proprias, collectas habere et inte se comparare.-Morgagrr. De Sed. et Caus. Morb. Lib. 11. Procemium.

\section{GUY'S AND ST. MARY'S HOSPITALS.} AMPUTATIONS AT THE ANKLE-JOINT.

(Performed by Mr. BirketT and Mr. Ure.)

CASE 1. - This operation is now so frequently performed at the various hospitals of this metropolis, that putting them upon record can have but a statistical interest. It would, however, be very desirable, as to statistics, if the profession could learn, by well-arranged figures, the per centage of cases where the flap sloughs, and also the proportion of patients who eventually are enabled to make a satisfactory use of the stump. But this is not this day our object, we wish merely to aequaint our readers with certain modifications in the operation which bears $\mathrm{Mr}$. Syme's name. One of these consists in an attempt to render the plantar flap firmer and more resisting; the other in the sawing of the thin plate of bone on the lower portion of the tibia and fibula, without disarticulating, after the soft parts have been dissected into the proper flaps. The latter modi. fication was lately introduced by Mr. Birkett at Guy's Hospital, the former by Mr. Ure at St. Mary's.

Mr. Birkett's patient is a young man, about twenty years of age, who has been suffering for some time from scrofulous caries of the metatarsus. An operation had been undertaken some 
months before the one which we are going to describe, and consisted of the removal of almost the whole metatarsal bone of the great toe. The results of this measure had not been of a satisfactory kind, and the patient, wearied by suffering and debilitated by suppuration, requested amputation. On the 7 th of November, Mr. Birkett proceeded to remove the foot in the following manner:-The usual incision was first made across the instep, and the soft parts dissected upwards to a short extent; the knife was then carried across the sole of the foot from one of the extremities of the upper incision to the other, and Mr. Birkett now began a dissection upwards and backwards at the back of the os calcis, until he arrived behind the tibio-tarsal articulation. He thus obtained a large and sufficient posterior flap, and then formed a complete anterior one, in dissecting upwards from the original line of incision until he had reached about half an inch above the upper articular surface of the astragalus. The saw was now applied across the malleoli, and these processes were removed with the thin plate of bone of the lower articular surface of the tibia, which is generally taken off in Syme's amputation at the ankle-joint.

It will be perceived that Mr. Birkett did not disarticulate at all, as is ordinarily done in this operation; and if we may be allowed to express the effect of this modified amputation upon the spectator, we rould say that the whole proceeding looked very effective and secure. Of course this modification can hardly have any material influence on the ultimate results of the amputation; but it may perhaps be looked upon as a step towards simplifying the operation. Mr. Birkett, in examining the foot after the operation, drew attention to the work of repair which had been going on at the site where bone lad originally been removed; union had taken place by means of firm, fibrous tissue. Some sloughing of the flap has since taken place, but the patient is now doing well, and likely to recover with an useful stump. Let us now turn to the second modification of Syme's amputation at the ankle-joint.

\section{ST. MARY'S HOSPITAL}

AMPUTATION AT THE ANKLE-JOINT. (Performed by Mr. URE.)

OASE 2. - Thomas P_-_, aged nineteen years and a half, was admitted on 17 th March, 1854. He has sandy hair, grey irides, and tumid upper lip. About eight months previously he was attacked with pain and swelling of the right instep. Eight weeks subsequently an abscess formed, and burst in two places, one near the inner side of the dorsum, the other near the ball of the great toe. He was confined to the house, but still followed his employment, that of a grocer's assistant, in spite of the discharge, till about a fortnight before his admission into the hospital, during which period he had attended, without benefit, at a dispensary. The patient was unable to assign any cause for the swelling of the foot, which was nearly double its natural size. There was a sinuous opening about one inch and a half from the angle between the first and second toes; and another near the tarsal end of the fifth metatarsal bone. Through both of these, carious bone could be detected by means of a probe. The man complaimed of pain at the instep when standing up; he was lethargic, subject to occipital headache, and his mind occasionally wandered during the night; his pulse was quick, tongue furred, and his bowels were costive.

Mr. Urewas led, from the general appearance and symptoms of this patient, to infer tubercular disease of the brain.

Fourth day after admission.-An abscess formed over the metatarsal end of the great toe, which was opened; at the bottom of it diseased bone was discoverable.

As there was no prospect of improvement, Mr. Ure, on the $22 n d$, amputated the great toe, removing, at the same time, about an inch of the adjoining portion of the metatarsal bone. This latter portion of bone, and the proximal plualanx, were both affected with caries. He likewise gonged ont the carious surface of the fifth metatarsal bone.

Tenth day after the operation.-.The patient complained of severe headache the preceding evening, which was relieved by the application of two leeches; after which he slept well. The skin was cool; pulse 120; bowels were open. He took with relish his daily allowance of food. The wound seemed healing, and was dressel with dilute solution of chloride of soda.

Towards the middle of April-namely, twenty-five days after the operation-the wounds were nearly cicatrized, but the foot continued swollen, and two sinuous ulcers formed a a little below the instep.

A fortnight afterwards the man's appetite began to flag, having previously been good. There was no discharge from the openings, but the surface appeared inflamed, at times tender and puffy.

As the disease had evidently extended to the tarsus, and his health and strength, about two months after the remoral of the great toe, were manifestly giving way, it was determined, on consultation, to amputate the foot at the ankle-joint, which was done as follows, on the 24 th of May, by Mr. Cre.

The patient having been rendered insensible by chloroform, an oval incision was made across the instep, from one ankle to the other, and the knife was then carried in a semilumar direction across the sole of the foot, the points of both incisions being made to meet in front, a little below the malleoli. The tibio-tarsal articulation was then opened at the outer side, the internal lateral ligament divided, and the astragalus luxated. As the os calcis was sound, Mr. Ure removed with the saw its anterior portion, thereby leaving a thin plate of the convex posterior surface of the bone in the heel. After sawing off the malleoli, together with a thin disc of the articular surface of the tibia, and securing the tibial arteries, the above-mentioned portion of os calcis was brought into as close apposition as possible with the cut surface of the tibia. - This last step was not effected in a satisfactory manner, owing to the retractile agency of the tendo Achillis; and Mr. Ure conceives that advantage would be gained in any similar operation, by a preliminary subcutaneons division of that tendon. The edges of the wound were then placed in contact, and retained by means of sutures, a fold of wet lint laid over the stump, and the patient conveyed to bed. The ends of the metatarsal bones, and the bones of the tarsus, with the exception of the astragalus and os calcis, were extensively carious. The synovial membranes were in a state of pulpy degeneration. Both the diseased synovial membranes and the cancellous texture of the affected bones were infiltrated with tubercular corpuscles. These consisted of irregular ovoid corpuscles, containing from six to eight dark molecules.

First day after amputation at the ankle-joint.-Slept well the first part of the night, after having taken an opiate; pulse 80 ; tonoue dry and rather glazed; no complaint of any kind; he enjoyed his breakfast; there is a slight oozing of sero-sanguinolent fluid from the wound.

Second day.-Slept tolerably well; took his dinner with relish, along with a pint of porter; pulse 120 ; tongue moist; there was a faint blush of red, extending about six inches up the limb from the stump; the stump itself was looking favourably.

Third day. - Slept well; pulse quick; tongue moist; appetite good; margins of the wound suppurating; dilute solution of chloride of soda as a dressing.

Fifth day.-Pulse 120, more firm than previously; enjoying his daily food; tongue clean; bowels open; edges of the wound somewhat sloughy; the end of the tibia can be felt. Exythematous blush was arrested by peneilling the margin with nitrate of silver.

Sixth day.-Pulse continued quick; wound was granulating at the outer angle; temperature of the under flap natural. Compound tincture of benzoin as a dressing under a linseed poultice.

Eighth day.-Has been several times sick; a good deal of the lower end of the tibia laid bare through partial destruction of the flap by sloughing; discharge copious. Mr. Ure ordered one minim of creasote in three drachms of compound galbanum. pill to be taken thrice a day.

Eleventh day. - Edges of the wound looked healthier than before; discharge thick and yellow; tongue red; face flushed; bowels open; skin cool; pulse 108; passed a good night; vomiting was stopped by the creasote and galbanum pills.

Fifteenth day. - Pulse 120; about an inch of the surface of the tibia exposed, from which granulations are sprouting; discharge healthy, and diminished in quantity; painful sensation in the stomach after taking food. Mr. Ure ordered three grains of extract of conium and two of dried socla to be taken three times a day.

Sixteenth day.-Countenance improved; tongue clean; slept well; no return of vomiting or pain in the stomach; bowels rather costive; stump looked well; discharge still further diminished; granulations bealthy.

Twenty-sixth day.- Stump has made favourable progress discharge copious; pulse 120; countenance pale; expressed himself as on the whole improved in health; appetite was good; slept well; has latterly had six ounces of wine in the day, two ounces of brandy, together with a liberal allowance of food. He was now ordered five grains of citrate of iron and quinine in a pill, to be taken thrice a day; dilute solution of chloride of soda as a dressing.

Twenty-ninth day. - Much better in bodily health. 